P. Р. Мавлютов, М. К. Беляев. К вопросу роста трудовой мобильности российских граждан в контексте цифровизации общества

Научная статья

УДК 332.13

DOI: $10.18101 / 2304-4446-2021-2-33-42$

\title{
К ВОПРОСУ РОСТА ТРУДОВОЙ МОБИЛЬНОСТИ РОССИЙСКИХ ГРАЖДАН В КОНТЕКСТЕ ЦИФРОВИЗАЦИИ ОБЩЕСТВА
}

(С Мавлютов Рамиль Ростемович

кандидат экономических наук, доцент ramil-2002@mail.ru

(C) Беляев Михаил Константинович

доктор экономических наук, профессор

belyaev.m.k@mail.ru

Волгоградский государственный технический университет Россия, 400005, г. Волгоград, пр. им. Ленина, 28

\begin{abstract}
Аннотация. Последнее десятилетие показало рост уровня трудовой мобильности россиян в полтора раза; по данным официальной статистики, 4\% экономически активного населения занято вне пределов региона своего постоянного проживания. В статье представлены результаты исследования условий формирования трудовой мобильности в новой реальности - развития цифровой экономики, пандемии COVID-19. Установлено, что имеет место формирование благоприятного фона для смягчения нарастающего дисбаланса рабочей силы. Его основой должен стать переход к дистанционному (удаленному) формату работы с одновременной дезурбанизацией крупных городов. Часть занятых домашним хозяйством граждан может изменить место своего постоянного проживания на пригород, а также территории в черте города вблизи его административных границ. Они становятся благоприятными зонами для ведения бизнеса, что создает базу для трудовой миграции второй волны. Исследование может быть востребовано представителями органов власти, хозяйствующими субъектами, а также учеными, которые проводят изыскания в данной области.
\end{abstract}

Ключевые слова: трудовая мобильность, дистанционная (удаленная) работа, цифровизация, COVID-19, крупный город, пригород, миграция, дезурбанизация

\section{Для цитирования}

Мавлютов Р. Р., Беляев М. К. К вопросу роста трудовой мобильности российских граждан в контексте цифровизации общества // Вестник Бурятского государственного университета. Экономика и менеджмент. 2021. № 2. С. 33-42.

На современном этапе императивом развития мировой экономики является цифровизация. При этом означенная тенденция охватывает все сферы жизнедеятельности граждан вне зависимости от принадлежности к тому или иному государству. Здесь индивид обоюдно вовлечен в процесс и как потребитель, и как наемный работник, работодатель. Особое значение в контексте рассматриваемого вопроса занимают два фактора. Во-первых, трансформация процессов производства товаров и оказания услуг, являющихся традиционно не переносимыми в географическом пространстве и, следовательно, неторгуемых в ранг торгуемых, что происходит за счет снижения издержек перемещения. Вторым фактором яв- 
ляется кардинальное преобразование на рынке труда, в первую очередь в традиционных отраслях и традиционных профессиях. Начиная с весны 2020 г. свой особый вклад в разворачивающийся процесс внесла пандемия COVID-19, которая заставила кардинально пересмотреть взгляды на сложившееся течение событий. Совокупность приведенных явлений требует рассмотрения с позиции роста трудовой мобильности граждан России, контекст которой формирует цифровизация общества. Цель исследования - выявление основных тенденций изменения трудовой мобильности граждан России в условиях развития цифровой экономики.

Информационную базу исследования составили данные Федеральной службы государственной статистики, научные статьи периодических изданий, аналитические доклады, законодательные акты Российской Федерации, материалы свободного доступа сети Интернет. Методами исследования выступили анализ, синтез, группировка, обобщение.

Развитие информационно-телекоммуникационных сетей постепенно вовлекло все страны в единый процесс цифровизации мировой экономики. И с момента зарождения концепции цифровой экономики, точкой отчета которому признано применение в 1995 г. Николасом Негропонте метафорического высказывания, произошло кардинальное изменение видения ее основных положений и, прежде всего, самого понятия цифровой экономики. Особенно примечательная эволюция, свидетелями которой мы стали в течение последнего десятилетия: электронная коммерция; деловые операции, основанные на сети Интернет; форма экономической активности, возникающая благодаря множеству сетевых воздействий; инструмент снижения бедности и социального неравенства. В рамках настоящего исследования под цифровой экономикой понимается деятельность по созданию, распространению и использованию цифровых технологий и связанных с ними продуктов и услуг [1].

Одновременно Стратегия развития информационного общества РФ на 20172030 гг. ${ }^{1}$ в качестве стратегической цели трансформации национальной экономики устанавливает переход к хозяйственной деятельности, для которой в качестве ключевого фактора производства должны стать данные в цифровом виде, их обработка с последующим применением результатов их интерпретации. Результатом чего должно стать значительное повышение результативности различных производств, видов оборудования, процесса хранения и последующей продажи, доставки товаров и услуг.

Свой особый вклад в разворачивающийся процесс цифровизации экономики внесла пандемия COVID-19, которая начиная с весны 2020 г. заставила кардинально пересмотреть взгляды на сложившееся течение событий. С 30 марта 2020 г. начал отсчет нового этапа в организации труда граждан России. Указом В. Путина ${ }^{2}$ был введен дистанционный (удаленный) режим работы для подавля-

${ }^{1}$ О Стратегии развития информационного общества в Российской Федерации на 2017 2030 годы: указ Президента РФ от 9 мая 2017 г. № 203. URL: https://base.garant.ru/71670570/ (дата обращения: 20.03.2021). Текст: электронный.

${ }^{2}$ Об объявлении в Российской Федерации нерабочих дней: указ Президента РФ от 25 марта 2020 г. № 206. URL: https://www.garant.ru/products/ ipo/prime/doc/73693643/ (дата обращения: 22.03.2021). Текст: электронный. 
Р. Р. Мавлютов, М. К. Беляев. К вопросу роста трудовой мобильности российских граждан в контексте цифровизации общества

ющего большинства занятых, исключением стали лишь сотрудники ограниченного числа организаций, среди которых непрерывно действующие, медицинские и аптечные, часть торговых. В течение 2020 г. российское общество, так же как и иностранные граждане, столкнулось с невиданным вызовом для современности, ответом на который стал тотальный переход занятых на до того момента считавшийся не столь распространенной практикой режим выполнения трудовой функции не на рабочем месте, а дистанционно, находясь в месте постоянного проживания. Логическим итогом этого стало законодательное оформление формирующейся практики посредством внесения изменений в трудовое законодательство Российской Федерации, прежде всего - Трудовой кодекс РФ ${ }^{1}$. В означенный документ введена глава 49.1 «Особенности регулирования труда дистанционных работников», которая вступила в силу 1 января 2021 г.

В рамках масштабного исследования принципов организации удаленной работы российским бизнесом в 2020 г. было установлено, что 84\% компаний находят преимущества как для бизнеса, так и для сотрудников (рис. 1). Тема самым повышается привлекательность дачных поселков как места постоянного жительства и выполнения трудовой функции, причем как в рамках крупного города, так и регионов.

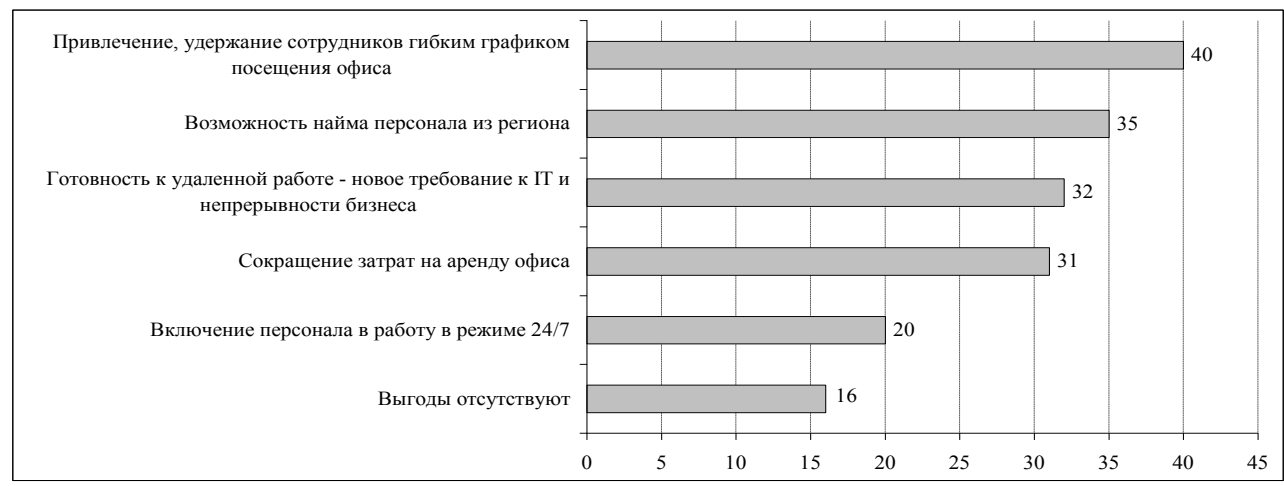

Рис. 1. Выгоды от дистанционной (удаленной) работы по результатам обследования предприятий основных секторов экономики России по итогам работы в 2020 г., \% обследованных предприятий ${ }^{2}$

С позиций наемных работников работа в дистанционном (удаленном) режиме имеет ряд преимуществ: свобода перемещений; экономия времени по причине отсутствия необходимости перемещения к месту работы и обратно (по крайней мере, в ежедневном режиме в строго установленные временные промежутки); возможность организации рабочего места под себя, руководствуясь своими индивидуальными потребностями. Однако здесь с позиций инфраструктуры возникает необходимость обязательной организации постоянного доступа к информа-

1 Трудовой кодекс Российской Федерации от 30 декабря 2001 г. № 197-Ф3. URL: https://base.garant.ru/12125268/ (дата обращения: 23.03.2021). Текст: электронный.

${ }^{2}$ Исследование: как крупный российский бизнес будет развивать технологии удаленной работы. URL: https://www.cnews.ru/articles/2021-01-26_cnews_analytics_ itogi_udalenki 2020_i_budushchie (дата обращения: 25.03.2021). Текст: электронный. 
ционно-телекоммуникационным сетям, технического обеспечения (персональный компьютер, мультимедийные устройства и т. д.). Отметим, что в 2020 г. доступ к интернету имело 76,6\% домашних хозяйств России, а к широкополосный доступ к интернету имело $73,2 \%{ }^{1}$. При этом в российских организациях широкополосный доступ к интернету имели лишь $65,4 \%$ хозяйствующих субъектов [2]. Таким образом, доступность интернета населения заведомо выше того, что наблюдается применительно к организациям. Кроме того, наличие доступа априори предопределяет наличие технического обеспечения, необходимого для его использования. Одновременно существует практика его предоставления работодателем. В связи с этим инфраструктурный вопрос не имеет актуальности, либо в отдельных случаях разрешим с необходимостью приложения минимума дополнительных организационных усилий.

Неравномерность социально-экономического развития отдельных регионов России, а также входящих в их состав муниципальных образований, на протяжении без малого трех последних десятилетий стала первостепенной движущей силой трудовой миграции внутри России. С позиций своего бюджета каждый регион России признается финансово самостоятельным, однако центральные государственные органы производят перераспределение доходов бюджетной системы России в рамках консолидированного бюджета между бюджетами различных уровней бюджетной системы. Красноречиво отражает сложившуюся на текущий момент картину перечень субъектов Российской Федерации, которые не являются получателями дотаций на выравнивание бюджетной обеспеченности, ежегодно утверждаемых Минфином РФ. На 2001 г. в состав означенного перечня входит лишь 13 субъектов. Это прежде всего г. Москва и Санкт-Петербург, Московская и Ленинградская области, Татарстан, Калужская область, Самарская область, Сахалинская область, Свердловская область, Тюменская область, Ненецкий автономный округ, Ханты-Мансийский автономный округ - Югра, ЯмалоНенецкий автономный округ ${ }^{2}$. Именно они по причине более высокого уровня качества жизни (более высокий уровень заработной платы, перспективы карьерного роста, развитость социальной инфраструктуры) выступают точками притяжения потоков трудовой миграции. При этом число таких регионов с течением времени менялось. Если по состоянию на 1993 г. их было 35, то в 1997 г. их число сократилось вчетверо - до 8, в 2001 г. возросло до 25.

Рассмотрим статистические данные по численности постоянного населения по регионам России за период 2012-2020 гг. (табл. 1). Анализу подвергнем регионы-реципиенты, а также два региона, которые не входят в их число. Во-первых, это Волгоградская область - субъект с хроническим дефицитом регионального бюджета (доля дотаций из федерального бюджета превышает 10\% объема доходов консолидированного бюджета региона), в прошлом являвшийся промышлен-

\footnotetext{
1 Росстат опубликовал данные по проникновению ШПД в регионах России. URL: https://d-russia.ru/rosstat-opublikoval-dannye-po-proniknoveniju-shpd-v-regionah-rossii.html (дата обращения: 25.03.2021). Текст: электронный.

${ }^{2}$ Об утверждении перечней субъектов Российской Федерации в соответствии с положениями пункта 5 статьи 130 Бюджетного кодекса Российской Федерации: приказ Минфина России от 11 ноября 2020 г. № 1030. URL: https://www.garant.ru/products/ipo/ prime/doc/74864896/ (дата обращения: 27.03.2021). Текст: электронный.
} 
Р. Р. Мавлютов, М. К. Беляев. К вопросу роста трудовой мобильности российских граждан в контексте цифровизации общества

ным центром Юга России. Во-вторых, Краснодарский край - относительно благополучный субъект, имеющий значительный рекреационный потенциал, который был усилен проведением в 2014 г. XXII Олимпийских зимних игр в г. Сочи.

Таблица 1

Численность постоянного населения по регионам России, тыс. чел. на 1 января ${ }^{1}$

\begin{tabular}{|l|c|c|c|c|c|c|c|c|c|}
\hline $\begin{array}{l}\text { Наименование } \\
\text { региона }\end{array}$ & 2012 & 2013 & 2014 & 2015 & 2016 & 2017 & 2018 & 2019 & 2020 \\
\hline г. Москва & 11541 & 11980 & 12108 & 12198 & 12330 & 12381 & 12506 & 12615 & 12678 \\
\hline $\begin{array}{l}\text { г. Санкт- } \\
\text { Петербург }\end{array}$ & 4899 & 5028 & 5132 & 5192 & 5226 & 5282 & 5352 & 5384 & 5398 \\
\hline $\begin{array}{l}\text { Московская } \\
\text { область }\end{array}$ & 7106 & 7048 & 7134 & 7231 & 7319 & 7424 & 7503 & 7600 & 7691 \\
\hline $\begin{array}{l}\text { Ленинградская } \\
\text { область }\end{array}$ & 1719 & 1751 & 1764 & 1776 & 1779 & 1792 & 1813 & 1848 & 1876 \\
\hline $\begin{array}{l}\text { Тюменская } \\
\text { область }\end{array}$ & 3405 & 3511 & 3546 & 3581 & 3616 & 3660 & 3692 & 3724 & 3757 \\
\hline $\begin{array}{l}\text { Волгоградская } \\
\text { область }\end{array}$ & 2607 & 2583 & 2569 & 2557 & 2546 & 2535 & 2521 & 2508 & 2491 \\
\hline $\begin{array}{l}\text { Краснодарский } \\
\text { край }\end{array}$ & 5230 & 5330 & 5404 & 5453 & 5514 & 5571 & 5603 & 5648 & 5675 \\
\hline $\begin{array}{l}\text { Россия в целом, } \\
\text { млн чел. }\end{array}$ & 142,8 & 143,3 & 143,7 & 146,3 & 146,5 & 146,8 & 146,9 & 146,8 & 146,7 \\
\hline $\begin{array}{l}\text { Россия в целом } \\
\text { без учета } \\
\text { Республики Крым } \\
\text { и г. Севастополь, } \\
\text { млн чел. }\end{array}$ & 142,8 & 143,3 & 143,7 & 144,0 & 144,2 & 144,5 & 144,5 & 144,4 & 144,3 \\
\hline
\end{tabular}

Согласно таблице 1, за 2012-2020 гг. численность населения России в целом возросла с 142,8 млн чел. до 146,7 млн чел., то есть на 3,9 млн чел. Однако значительную часть в указанном приросте составляет увеличение численности населения по причине присоединения территорий Севастополя и Крыма, суммарная численность населения которых по итогам переписи населения (в октябре 2014 г.), равна 2,3 млн чел. ${ }^{2}$, а к 2018 г. приросла до 2,4 млн чел. Таким образом, естественный прирост (в силу демографических причин) населения России за 2012-2020 гг. составляет гораздо более скромную величину - 1,5 млн чел. (рис. 2).

\footnotetext{
1 Численность населения Российской Федерации по муниципальным образованиям. URL: https://rosstat.gov.ru/compendium/document/13282 (дата обращения: 28.03.2021). Текст: электронный.

${ }^{2}$ История статистики населения Крыма и Севастополя. URL: https://tass.ru/info/1651414 (дата обращения: 28.03.2021). Текст: электронный.
} 


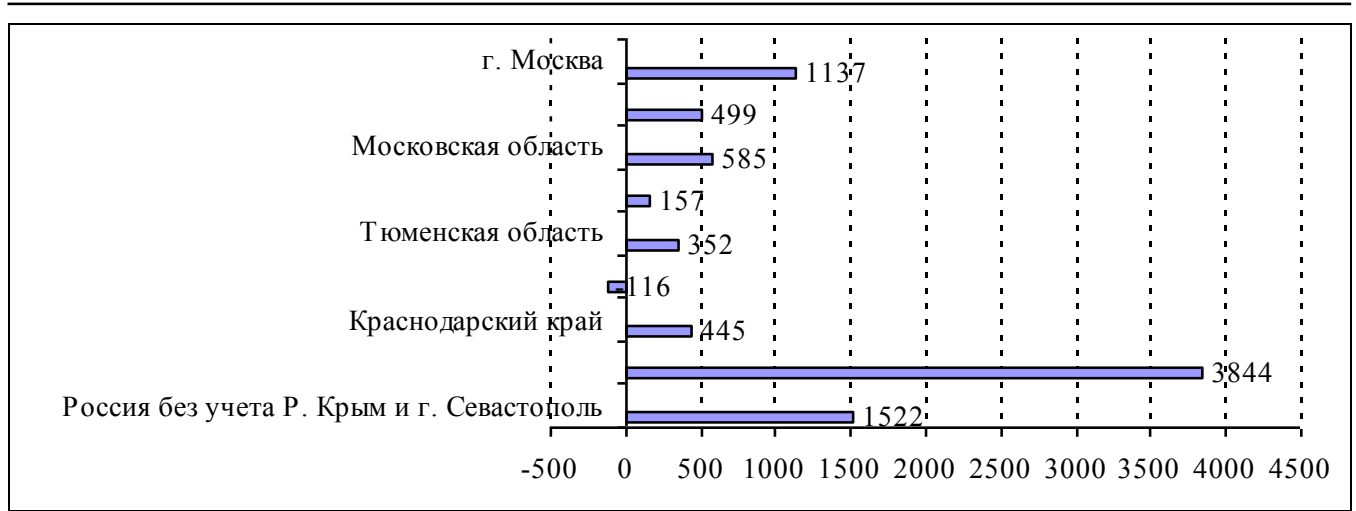

Рис. 2. Прирост численности постоянного населения по регионам России, 2020 г. к 2012 г., тыс. чел.

Оценить темпы прироста численности населения по отдельным регионам Российской Федерации можно по рисунку 3. Наибольшие подвижки в диапазоне 9$10 \%$ имели место в г. Москва, г. Санкт-Петербург, а также соответственно Московская область, Ленинградская область (рис. 3). Они, будучи центрами политической, экономической жизни страны неизменно пользуются вниманием россиян как место постоянного проживания. Однако лидером стала Тюменская область. Этот регион - нефтегазовая столица России, сосредотачивает на своей территории основную часть углеводородов страны, поэтому неизменно притягивает значительное количество вновь прибывающих граждан. И благоприятная конъюнктура мировых товарно-сырьевых рынков в дальнейшем будет поддерживать эту тенденцию. Одновременно следует обратить внимание на высокий уровень прироста населения в Краснодарском крае. За последние 9 лет население региона приросло на 8,5\%. Описанные явления нашли подтверждение в исследовании, проведенном HeadHunter в сентябре - октябре 2020 г. ${ }^{1}$, согласно которому наиболее привлекательной характеристикой Москвы является высокий уровень заработной платы (89\% опрошенных соискателей вакансий), применительно к Санкт-Петербургу это более комфортная городская среда (61\%), а вот комфортностью климата и хорошей экологической обстановкой привлекает к себе Краснодарский край $(88 \%)$.

Таким образом, на современном этапе мы констатируем наличие комплекса факторов, которые способны активизировать трудовую мобильность граждан России. При этом исследование истории вопроса демонстрирует, что точками притяжения являются такие городские агломерации, как Москва и СанктПетербург территории с наиболее высоким уровнем социально-экономического развития. К их числу примкнул Краснодарский край с наиболее благоприятными условиями проживания с точки зрения климата, экологии. Дальнейшее разворачивание означенной тенденции в среднесрочной и долгосрочной перспективе грозит усилением негативных факторов.

1 Исследование показало предпочтения россиян при переезде в другие регионы. https://ria.ru/20201026/pereezd-1581507019.html?utm_source=yxnews\&utm_medium=desktop (дата обращения: 29.03.2021). Текст: электронный. 
Р. Р. Мавлютов, М. К. Беляев. К вопросу роста трудовой мобильности российских граждан в контексте цифровизации общества

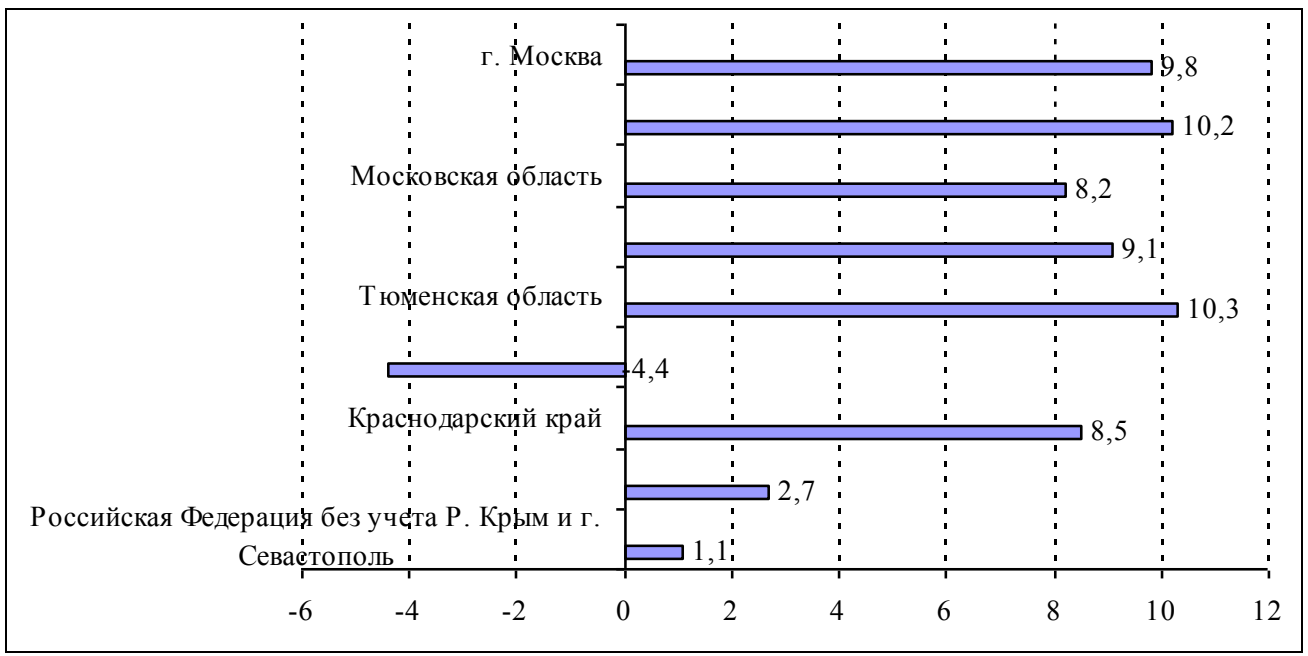

Рис. 3. Темпы прироста численности постоянного населения по регионам России, 2020 г. к 2012 г., \%

Во-первых, усугубление дисбаланса рабочей силы. Отдельные территории, отрасли, виды деятельности и занятий испытывают неудовлетворенный спрос на рабочую силу - особенно это важно применительно к высококвалифицированному труду. В этом состоит угроза полноценному развитию отдельных территорий, регионов и, следовательно, всего государства в целом. В этой же плоскости находится перманентное отсутствие баланса между спросом и предложением на рабочую силу в регионах Сибири, Дальнего Востока, Урала.

Во-вторых, городские агломерации Москва и Санкт-Петербург характеризуются избыточной нагрузкой на жилищно-коммунальную, транспортную, социальную инфраструктуру, которая в перспективе только будет возрастать. Вместе с тем любой крупный город, городская агломерация, является центром целого комплекса проблем, таких как жилье, демография, градостроительство, экология и т. д. В последнее время к ним примкнула проблема отсутствия возможности соблюдения в полной мере социальной дистанции в рамках мер по борьбе с пандемией COVID-19. Следует отметить, что эта проблема отнюдь не локального характера. Пандемия лишь обнажила ту болевую точку, которая прежде не давала о себе знать, но давно является фактором, требующим пристального внимания [3, с. 105].

Одним из основных направлений миграционной политики, реализуемой в период 2019-2025 гг. ${ }^{1}$, выступают содействие созданию благоприятных условий для внутренней миграции, понижение диспропорций в размещении населения. Реализация этого направления предусматривает наряду с прочим формирование рынка доступного жилья. С нашей точки зрения этому процессу должно содей-

${ }^{1}$ О Концепции государственной миграционной политики Российской Федерации на 2019-2025 годы: указ Президента РФ от 31 октября 2018 г. № 622. URL: https://www.garant.ru/products/ipo/prime/doc/71992260/ (дата обращения: 30.03.2021). Текст: электронный. 
ствовать развитие дезурбанизации. В рамках последней часть городского населения, которая выполняет трудовую функцию в удаленном (дистанционном) режиме, должна сменить место постоянного проживания на пригород, а также территории в черте города вблизи его административных границ. Здесь нами рассматриваются, прежде всего, крупные города России, которых по состоянию на начало 2021 г. насчитывается 15. Это города федерального значения Москва и СанктПетербург с населением соответственно 12,7 млн чел. и 5,4 млн чел., а также города с числом жителей 1-2 млн чел. (Новосибирск, Екатеринбург, Нижний Новгород, Казань, Челябинск, Омск, Самара, Ростов-на-Дону, Уфа, Красноярск, Пермь, Воронеж, Волгоград). В контексте пандемии COVID-19 2020 г. показал склонность граждан к смене места постоянного проживания, в пользу чего свидетельствует рост спроса на загородную недвижимость не только с позиций сезонного проживания на условиях аренды, но и покупки. Красноречивым результатом чего стал рост стоимости жилья вне пределов города в среднем по России на $11 \%$, а в отдельных регионах — на треть.

Следует ожидать значительного смягчения дисбаланса рабочей силы. Это должно произойти за счет найма работников из регионов без смены ими места постоянного проживания. С другой стороны, крупный город сможет быть обеспечен рабочей силой за счет граждан, проживающих на территории региона, административным центром которого он является. Одновременно снизится прирост нагрузки на инфраструктуру крупного города, городской агломерации. При этом смягчатся проблемы в части жилья, демографии, градостроительства, экологии.

Развитие бизнеса на территории пригорода укладывается в парадигму реализации рассмотренного выше (рис. 1) комплекса преимуществ удаленного (дистанционного) режима работы. Граждане, которые работают в означенном режиме, за счет формирования платежеспособного спроса становятся базой для развития предпринимательской деятельности на территории своего проживания. Их потребление, большая часть расходов сместится с территории физического местонахождения работодателя (а это может быть и другой регион, в отдельных случаях другое государство) на территорию постоянного проживания. Здесь уже следует говорить о трудовой миграции второй волны, основой которой становится те, кто обслуживает платежеспособный спрос, возросший по причине миграции граждан, работающих в удаленном (дистанционном) режиме. Наряду с этим привлекательность ведения бизнеса на территории пригорода крупного города обусловливается следующими факторами: малая удаленность от центров повышенной деловой активности, располагающихся в черте города; высокий уровень развития транспортной инфраструктуры; прирост доходности по причине непосредственной близости к рынкам сбыта, потребителям; менее высокий уровень конкуренции по сравнению с городом.

Здесь следует говорить об агломерационном эффекте, в качестве которого нами понимается некая пространственная синергия, которая сформировалась в пределах большого города и его пригородной зоны на основе использования специфического потенциала земельных и других природных ресурсов территории, урбанизированной концентрированной системы расселения и плотной сети коммуникаций [4, с. 37].

Таким образом, усиление процессов развития цифровой экономики, сопровождаемых мерами по борьбе с пандемией COVID-19, заставляет говорить о 
Р. Р. Мавлютов, М. К. Беляев. К вопросу роста трудовой мобильности российских граждан в контексте цифровизации общества

необходимости по-новому взглянуть на проблему трудовой мобильности граждан внутри России. Трудовая миграция порождает ряд негативных явлений, которые возможно смягчить посредством взаимного соблюдения интересов. Такой синергетический эффект складывается из заинтересованности представителей бизнеса в организации работы своих сотрудников в удаленном (дистанционном) режиме; склонности экономически активной части населения выполнять трудовую функцию по месту своего постоянного проживания. При этом снимается с повестки вопрос о необходимости создания благоприятных условий проживания для вновь пребывших трудовых мигрантов. Они, не покидая место постоянного проживания, создают базу для социально-экономического развития своего региона. Одновременно снижается нагрузка на инфраструктуру, смягчается острота комплекса перманентных проблем (жилье, демография, градостроительство, экология). Особенно это важно применительно к территориям, являющимся наиболее притягательными (городские агломерации Москвы и Санкт-Петербурга, Краснодарский край).

В качестве показательного примера приведем агломерацию г. Волгограда. Волгоградский регион в течение 2012-2020 гг. лишился 116 тыс. жителей (снижение на 4,4\%). По нашему мнению, значительная часть граждан, покинувших регион, могла бы остаться на его территории при условии наличия возможности выполнения трудовой функции в удаленном (дистанционном) режиме. Ведь главным сдерживающим фактором смены места постоянного проживания является обеспечение жильем. Одновременно существенное число потенциальных трудовых мигрантов от отъезда сдерживают плотные семейные связи. При этом региону характерны относительно благоприятный климат для постоянного проживания, сравнительно устойчивая экологическая обстановка. Кроме того, рекреационный потенциал региона наряду с прочим делает его притягательным для ведения предпринимательской деятельности.

\section{Литература}

1. Что такое цифровая экономика? Тренды, компетенции, измерение: доклад к XX Апрельской международной научной конференции по проблемам развития экономики и общества / Г. И. Абдрахманова, К. О. Вишневский, Л. М. Гохберг [и др.]; научный редактор Л. М. Гохберг; Нац. исслед. ун-т «Высшая школа экономики». Москва, 9-12 апр. 2019 г. Москва: Изд. дом Высшей школы экономики, 2019. 82 с. Текст: непосредственный.

2. Тенденции развития интернета в России и зарубежных странах: аналитический доклад / Г. И. Абдрахманова, О. Е. Баскакова, К. О. Вишневский [и др.]; Координационный центр национального домена сети Интернет, Нац. исслед. ун-т «Высшая школа экономики». Москва: НИУ ВШЭ, 2020. 144 с. Текст: непосредственный.

3. Мавлютов Р. Р. К вопросу оценки потенциала повышения эффективности управления в организациях жилищной сферы // Вестник Бурятского государственного университета. Экономика и менеджмент. 2020. № 4. С. 102-110. Текст: непосредственный.

4. Олейник В. Д., Гладкий А. В. Этапы развития и стадии формирования пригородных зон // Псковский региональный журнал. 2016. № 1(25). С. 31-44. Текст: непосредственный.

Статья поступила в редакцию 01.04.2021; одобрена после рецензирования 28.04.2021; принята к публикации 28.04.2021. 


\section{ON THE GROWTH OF LABOUR MOBILITY IN RUSSIA IN THE CONTEXT OF SOCIETY DIGITALIZATION}

Ramil R. Mavlyutov

Cand. Sci. (Econ.), A/Prof.

ramil-2002@mail.ru

Mikhail K. Belyaev

Dr. Sci. (Econ.), Prof.

belyaev.m.k@mail.ru

Volgograd State Technical University,

28 Prospect imeni Lenina, Volgograd 400005, Russia

Abstract. In the last decade the level of labour mobility of Russians went up one-and-a-half times; according to the official statistics $4 \%$ of economically active population is employed outside the region of their permanent residence. The article presents the results of a research on the conditions for labour mobility in a new reality of the digital economy development, and the COVID-19 pandemic. It has been established that there is a favorable background for lightening the growing imbalance of labour force. Distance (remote) working with the simultaneous de-urbanization of large cities will stimulate it. Some of the households, which include employed citizens, are willing to change their place of permanent residence to the suburbs, or the territories near the administrative boundaries of the city. These places are becoming favorable areas for doing business, and create the basis for the second wave of labour migration. The study may be useful for the representatives of government bodies, business entities, as well as for the researchers in this field.

Keywords: labour mobility, distance (remote) working, digitalization, COVID-19, large city, suburb, migration, de-urbanization.

\section{For citation}

Mavlyutov R. R., Belyaev M. K. On the Growth of Labour Mobility in Russia in the Context of Society Digitalization. Bulletin of Buryat State University. Economy and Management. 2021; 2: 33-42 (In Russ.).

The article was submitted 01.04.2021; approved after reviewing 28.04.2021; accepted for publication 28.04.2021. 